\title{
Percutaneous Microballoon Compression for Trigeminal Neuralgia Using Dyna-CT
}

\author{
HUO XIAOCHUAN, S. XIAOYUN, LUO JUNSHENG, GUAN NING, GUO WENSHI, \\ ZHANG ZHENXING \\ The First Affiliated Hospital of Liaoning Medical University; Jinzhou, Liaoning, China
}

Key words: trigeminal neuralgia, microballoon compression, dyna-CT

\section{Summary}

Percutaneous microballoon compression $(P M C)$ is a well-established technique for treatment of trigeminal neuralgia (TN). However, direct puncture of the foramen ovale $(F O)$ is sometimes difficult and there have been well-reported complications from cannulating the FO. We describe our experiences in using Dyna-CT for cannulating the FO and determining balloon position and volume.

Dyna-CT was used to perform image reconstruction in 21 cases. The optimal working projection was generated and further fluoroscopic data were used to determine the needle's relationship to the foramen during puncture. Furthermore, the balloon position and three-dimensional shape were verified by Dyna-CT during balloon compression. The balloon volume and puncture angle were further calculated. Patients' prognosis was further discussed.

Dyna-CT allowed quick, safe, and easy cannulation of the FO. It provided three-dimensional images which were more elaborate than the classic 'pear-shaped' images for determining correct positioning in 21 cases. The volume of the flattened balloon ranged from $568.2 \mathrm{~mm}^{3}$ to $891.4 \mathrm{~mm}^{3}$ with an average of $775.9 \mathrm{~mm}^{3}$. The angle of introducing the cannula ranged from $15.17^{\circ}-35.48^{\circ}$ rotation to the midline with an average of $26.24^{\circ}$ and $38.47^{\circ}-51.89^{\circ}$ angulation to the Reid line with an average of $46.09^{\circ}$. All the patients were pain free after PMC. Four patients had resolvable masseter weakness and fine touch loss. There was no recurrence of TN during follow-up.

Dyna-CT demonstrated three advantages in assisting PMC. Firstly, the FO can be better visualized irrespective of the patient's position. Sec- ondly, needle correction or insertion can be performed much more easily because of the direct fluoroscopic control. Thirdly, the needle position, balloon position, balloon configuration and the volume of the inflated balloon are more reliably determined. The use of dyna-CT provided an assisted method to PMC with a low incidence of complications and good prognosis.

\section{Introduction}

In the 1950s, intraoperative manipulation of the trigeminal ganglion was performed for the treatment of trigeminal neuralgia $(\mathrm{TN})^{1}$. Since then, several other techniques developed including microvascular decompression and several percutaneous techniques. In 1983, Mullan and Lichtor introduced the technique of percutaneous balloon compression for $\mathrm{TN}^{2}$. Percutaneous balloon compression is safe and straightforward and has the advantage of requiring only a short period of general anesthesia and no special equipment. Some investigators have advocated that it should be the procedure of choice in older patients with $\mathrm{TN}^{3-5}$.

However, there appears to be a higher incidence of masseter muscle weakness and dysesthesia after balloon compression ${ }^{6}$. Moreover, balloon compression can occasionally make it difficult to cannulate the foramen ovale (FO). Significant morbidity has been reported due to needle misplacement ${ }^{7}$. Correct cannulation is important for successful balloon compression and as described in the literature it is critical to confirm the balloon's ideal 'pear-shape' which predicts a good response as it compresses the region of the semilunar ganglion ${ }^{8}$.

Here, we describe an assisted technique for 


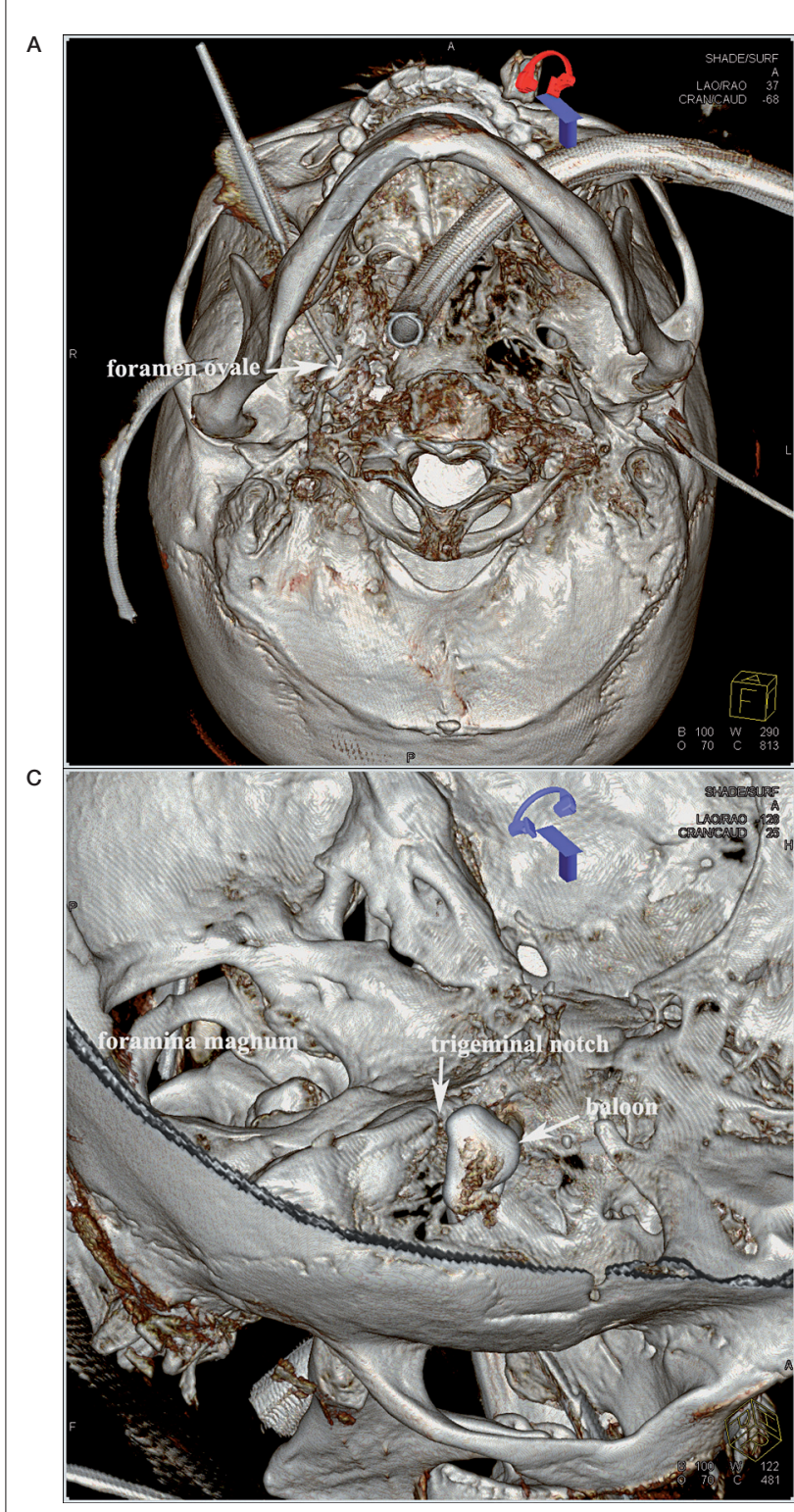

percutaneous microballoon compression (PMC) using dyna-CT which may correlate with clinical outcome. Dyna-CT helps visualize the foramen and allows easier cannulation of the $\mathrm{FO}^{9}$. It allows visualization of not only the tip of the needle in the foramen but also the size and shape of the inflated balloon. Better configuration of balloon in the skull base could shorten compression time which provides a good prognosis.

\section{Methods}

Under general anesthesia, surgery was performed in the neurointerventional suite with the patients in a supine position. Patients' heart

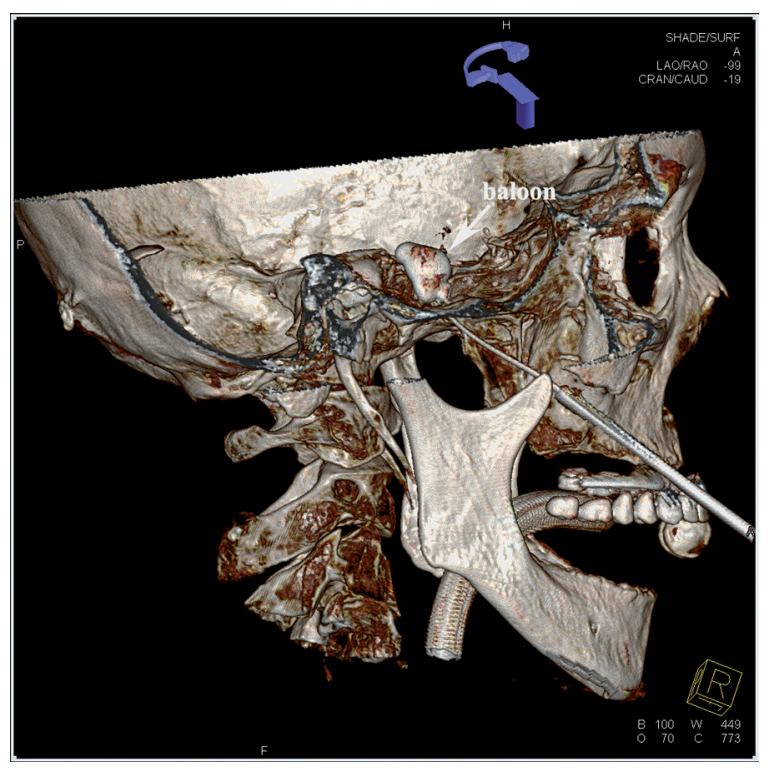

Figure 1

rate and blood pressure was monitored, atropine or nitroprusside sodium was used to treat the decreased heart rate and unstable blood pressure. Severe heart disease should be controlled before PMC. A temporary pacemaker was used as a precaution if necessary.

Using an Artis Zee Biplane system (Siemens, Erlangen, Germany), dyna-CT was first performed. On a dedicated workstation (SyngoXWP VB20D), automatic 3D reconstruction of the skull was completed in seconds. The FO was identified, with the optimal angle for best visualization chosen using 3D rotational software.

A 14-gauge introducing cannula, sharp and blunt obturators, a guiding wire, and a No. 4 Fogarty balloon catheter were used to perform the surgery. The side of the face relevant to the patient's pain was prepped and draped in a sterile fashion. The skin was punctured $2 \mathrm{~cm}$ lateral and $0.5 \mathrm{~cm}$ superior to the angle of the mouth. The 14-gauge introducing cannula with a sharp obturator was percutaneously passed to the FO using Härtel guidelines and aided by lateral fluoroscopic imaging. Once the cannula had reached the skull base, the sharp obturator was withdrawn and a blunt obturator was introduced through the introducing cannula. The submental view was obtained for the cannulation of $\mathrm{FO}$ as this view provides direct visualization of the FO. It is easy to feel when the 14-gauge cannula has engaged the FO. Often a 

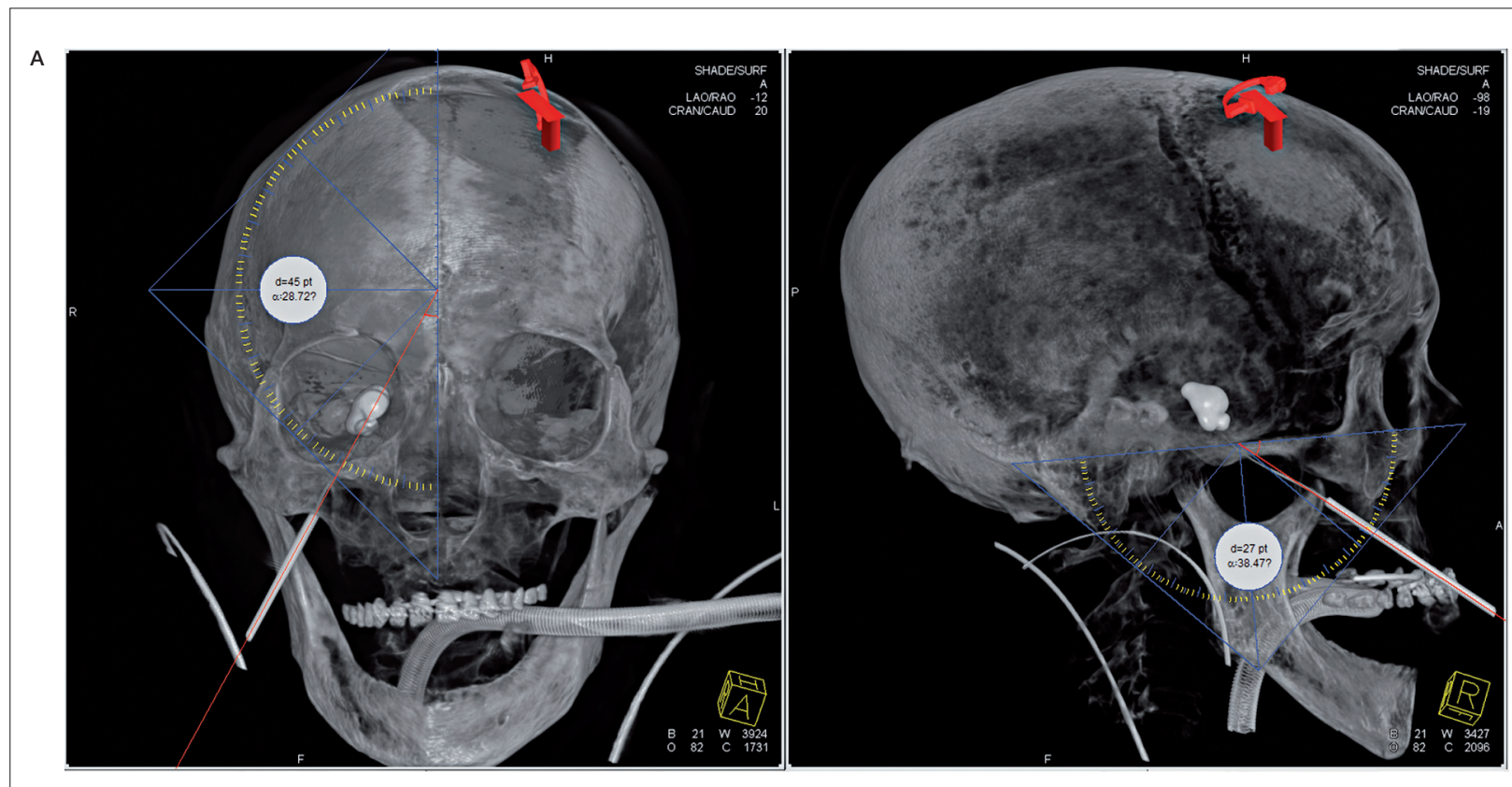

Figure 2

brief trigeminal depressor response occurs from mechanical compression of the mandibular nerve at the foramen. When a difficulty arose, additional 3D rotational fluoroscopy was performed to determine the relationship of the needle to the foramen.

Once the foramen is cannulated. The cannula should not pass beyond the FO, and cerebrospinal fluid is not seen when the cannula is properly positioned. A repeat $3 \mathrm{D}$ sequence can be performed to ascertain the exact position of the needle tip in relation to the depth of the foramen.

Once the cannula had engaged the foramen ovale, the blunt obturator was removed and the Fogarty balloon catheter with a guiding wire was introduced through the introducing cannula, pushed 1.2 to $1.4 \mathrm{~cm}$ beyond, and carefully navigated into Meckel's cave. The guiding wire of the catheter was then pulled out, and 0.6 to1.0 $\mathrm{ml}$ of Omnipaque was slowly injected into the catheter to inflate the balloon, which usually presented a 'pear' shape in the lateral view. After the balloon was maximally inflated, another 3D sequence could be performed (Figure 1), the volume could be calculated by an analysis system and the angles of cannulation were measured (Figure 2). The balloon was deflated and withdrawn after compressing the ganglion for three to four minutes. The whole procedure lasted less than 20 minutes. Depending on the technical difficulty encountered, some or all of the above dyna-CT might be required. With wider acceptance of this technique, it may be possible to further correlate the needle angle, balloon position and volume with clinical results.

\section{Results}

We used dyna-CT to treat a total of 21 patients. All the patients were treated with medications prior to PMC without sufficient pain relief. The median duration of the symptoms before PMC was six years, ranging from one year to ten years, no patient had undergone any surgery before. According to the Burchiel classification, there were 15 type $1 \mathrm{TN}$ and six type $2 \mathrm{TN}$. The mean fluoroscopy time per patient was $109.1 \mathrm{~s}$, ranging from $62 \mathrm{~s}$ to $165 \mathrm{~s}$, and the mean radiation dose per patient was 2202.8 $\mathrm{mGycm}^{2}$, ranging from $1386.4 \mathrm{mGycm}^{2}$ to $3593.9 \mathrm{mGycm}^{2}$. During compression, dyna-CT could provide $3 \mathrm{D}$ imaging and position of balloon in the skull base. The volume of the flattened balloon ranged from $568.2 \mathrm{~mm}^{3}$ to 891.4 $\mathrm{mm}^{3}$ with an average of $775.9 \mathrm{~mm}^{3}$. The angle of the introducing cannula ranged from $15.17^{\circ}$ $35.48^{\circ}$ rotation to the midline with an average of $26.24^{\circ}$ and $38.47^{\circ}-51.89^{\circ}$ angulation to the Reid line with an average of $46.09^{\circ}$. All the patients were pain free after PMC. Four patients had resolvable masseter weakness and fine 
touch loss. Follow-up time ranged from 16 to 37 months with an average of 24 months. There was no recurrence of TN during follow-up. Patients' demographics, clinical data and outcomes are summarized in Table 1.

\section{Discussion}

Percutaneous microballoon compression (PMC) is a simple and effective treatment for trigeminal neuralgia (TN) and especially useful in patients with first-division pain because it does not injure the myelinated fibers that mediate the blink reflex and thus does not lead to corneal keratitis ${ }^{8}$. However, PMC has been reported to be complicated by hypesthesia, dysesthesia, masseter muscle weakness, anesthesia dolorosa, corneal anesthesia, absent corneal reflex, aseptic meningitis, transient sixth nerve palsy, otalgia or trochlear nerve palsy, $6,8,10,11$. Due to these complications, some have sought measurement of balloon pressures to avoid these problems ${ }^{8}$. Our experiences showed that PMC was effectively performed with a balloon volume of 568.2-891.4 $\mathrm{mm}^{3}$ and the compression time ranged from three to four minutes. We will further test the balloon pressure and collect more patients to determine the relationship between prognosis, balloon pressure and volume.

The first essential step of PMC is the puncture of foramen ovale (FO). Anteroposterior and lateral fluoroscopy had been performed for two decades as a standard fluoroscopic technique ${ }^{12}$. Unfortunately, complications were reported for improper cannulating of the $\mathrm{FO}$ 13-18. These included wrongly cannulated foramina, inferior orbital fissure or foramen lacerum.

Dyna-CT is especially helpful when the FO cannulation is difficult or the operator has less experience. Three-dimensional (3D) imaging has revolutionized neurosurgical procedures. Meng et al. ${ }^{19}$ reported using a 3D CT scan to help needle placement. Van Gompel et al. ${ }^{20}$ performed the first dyna-CT scanning to determine the relationship of the balloon to Meckel's cave. Olivero et al. ${ }^{9}$ pointed out that $3 \mathrm{D}$ rotational fluoroscopy was an important adjunct for treating trigeminal neuralgia via percutaneous techniques. Some small cases reported the use of dyna-CT in PMC, but the study or analysis of balloon volume during compression was rarely presented.

We use dyna-CT to obtain three-dimensional imaging during the whole process of PMC for the treatment of TN. Dyna-CT not only helped us to obtain real-time visual guidance to cannulate the FO and determine the optimal position of the inflated balloon, it also provided valuable clinical data on the inflated balloon's exact shape and volume in Meckel's cave.

In our group, the incidence of masseter weakness and fine touch loss was 19\% right after PMC, but the complication disappear or significantly released in six months. Dysesthesia is the most common complication after PMC, and these complications were mostly mild and could disappear in 12 to 24 months. Dysesthesia occurs in $7-20 \%$ of the cases and may be related to the compression time ${ }^{2,12}$. The variable compression time was between 0.5 to 15 minutes and was not standardized. Compression time in recent reports mainly focused on 1 to $2 \mathrm{~min}^{8,21}$. On the basis of effective compression, less compression time could decrease complications. However, if compression time is not enough the pain will be unrelieved or likely to recur. Patients could accept dysesthesia more than unrelieved pain. Some operators subjectively increased the compression time which might leads to a higher permanent complication. In our experience, three to four minutes of compression with optimal balloon location morphology was advised for effective compression with fewer complications. Skirving et al. ${ }^{22}$ reported the recurrence of pain was $19.2 \%$ within five years and in $31.9 \%$ over the entire study period. The longest follow-up patient in our group is 37 months with no recurrent pain and further follow-up is needed in our group.

Our study also evaluated fluoroscopy time and radiation dose during PMC with dyna-CT. Patrick Fransen ${ }^{23}$ first presented a prospective case control study to document the level of radiation expected during percutaneous balloon compression of the Gasserian ganglion. Our data presented a longer fluoroscopy time and a higher radiation dose. That was because every dyna-CT added about 20 s (30F/s) and increased about $596.4 \mathrm{mSv}$ entrance dose during PMC. But it was appropriate to use dyna-CT in these cases for it faciliated puncture of the FO when difficulty occurred and provided important data for improvement of operation techniques.

We believe that dyna-CT provided important assistance for PMC. Firstly, the FO can be better visualized irrespective of the patient's position. Secondly, needle correction or insertion can be performed much more easily be- 


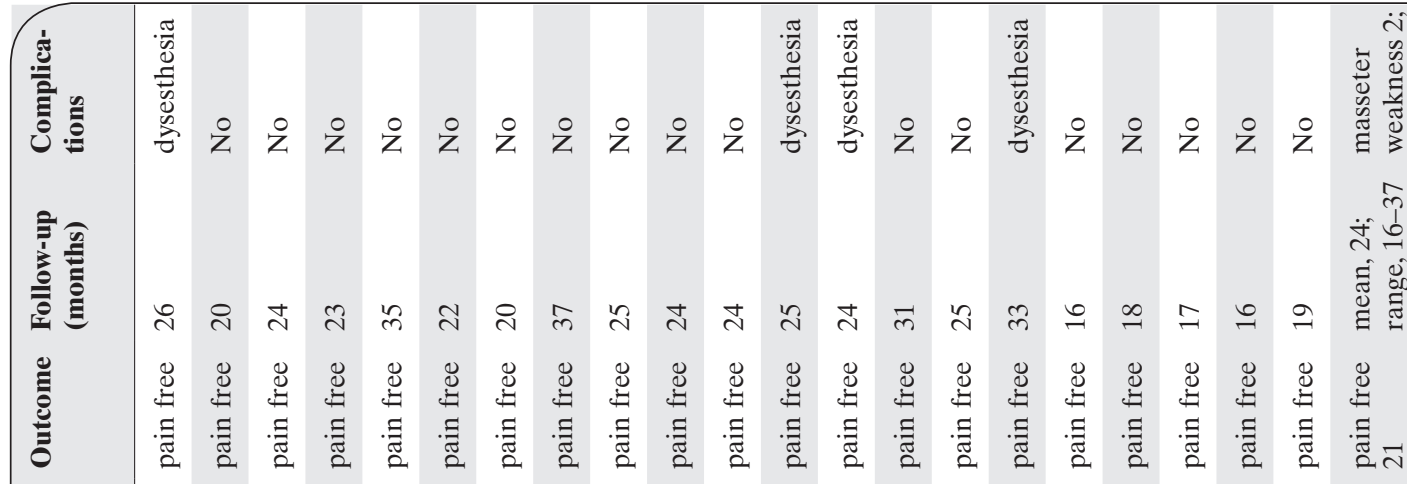

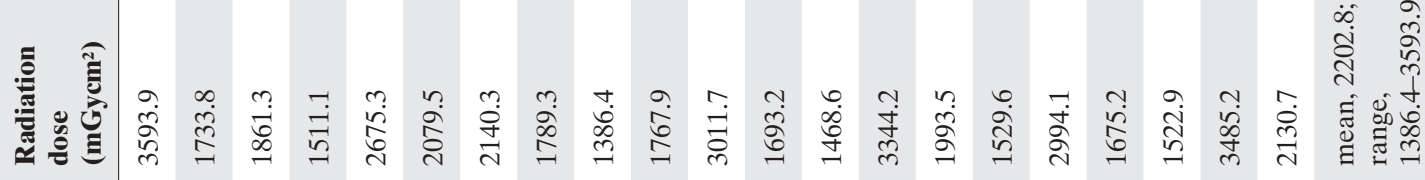

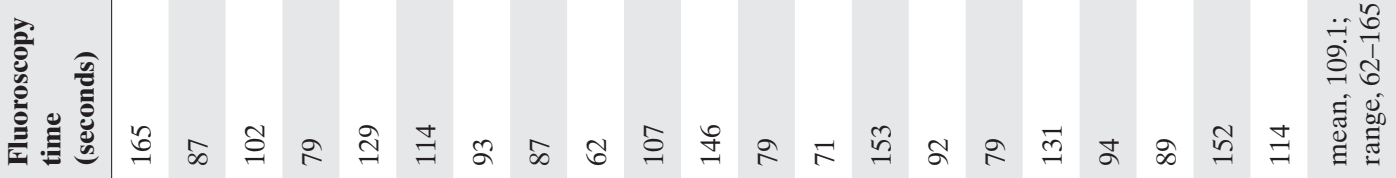

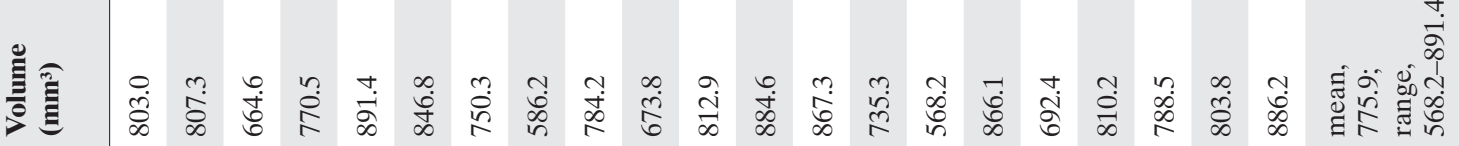

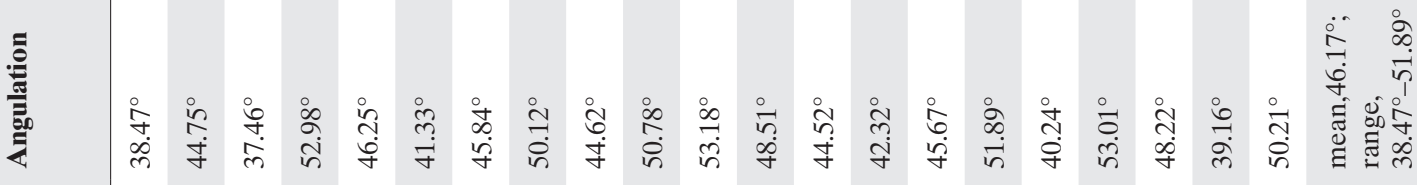

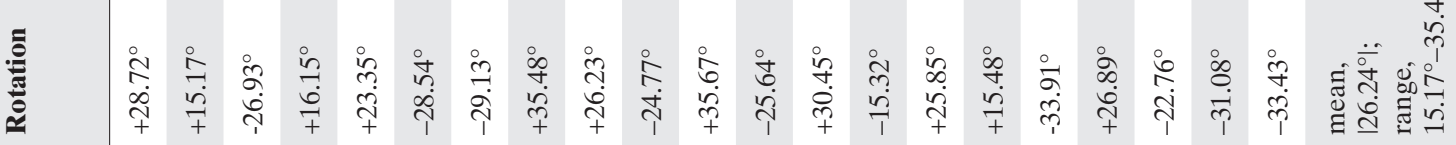

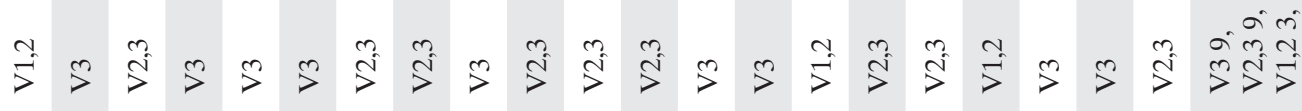

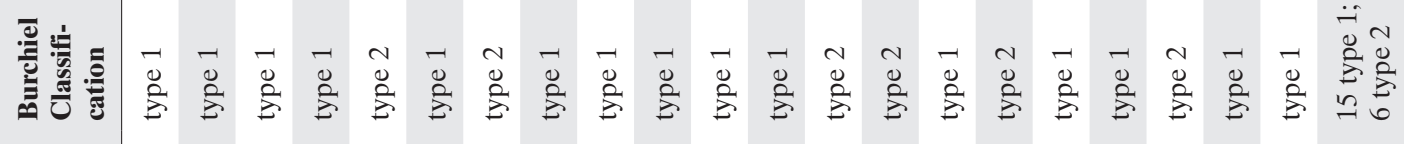

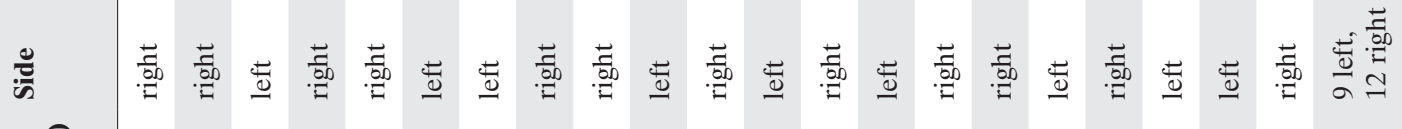

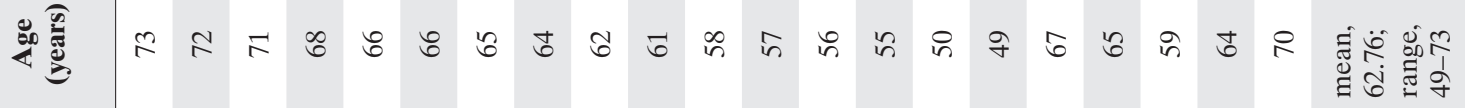
离 
cause of the direct fluoroscopic control. Thirdly, the needle position, balloon position, balloon configuration and the volume of the inflated balloon are more reliably determined. In our small cohort, the use of dyna-CT provided good assistance for PMC when cannulation was difficult and the incidence of complications was low.

\section{References}

1 Shelden CH, Pudenz RH, Freshwater DB. Compression rather than decompression for trigeminal neuralgia. J Neurosurg. 1955; 12: 123-128.

2 Mullan S, Lichtor T. Percutaneous microcompression of the trigeminal ganglion for trigeminal neuralgia. J Neurosurg. 1983; 59: 1007-1012.

3 Kouzounias K, Lind G, Schechtmann G, et al. Comparison of percutaneous balloon compression and glycero rhizotomy for the treatment of trigeminal neuralgia. J Neurosurg. 2010; 113: 486-492.

4 Lichtor T, Mullan JF. A 10-year follow-up review of percutaneous microcompression of the trigeminal ganglion. J Neurosurg. 1990; 72: 49-54.

5 Omeis I, Smith D, Kim S, et al. Percutaneous balloon compression for the treatment of recurrent trigeminal neuralgia: Long-term outcome in 29 patients. Stereotact Funct Neurosurg. 2008; 86: 259-265.

6 Brown JA, Gouda JJ. Percutaneous balloon compression of the trigeminal nerve. Neurosurg Clin N Am. 1997; 8: 53-62.

7 Kaplan M, Erol F, Ozveren M, et al. Review of complications due to foramen ovale puncture. J Clin Neurosci. 2007; 14: 563-568

8 Brown JA, Pilitsis JG. Percutaneous balloon compression for the treatment of trigeminal neuralgia: Results in 56 patients based on balloon compression pressure monitoring. Neurosurg Focus. 2005; 18: E10.

9 Olivero WC, Wang H, Rak R, et al. Percutaneous balloon rhizotomy for trigeminal neuralgia using threedimensional fluoroscopy. World Neurosurg. 2012; 77 : $202 \mathrm{e} 1-3$.

10 Abdennebi B, Bouatta F, Chitti M, et al. Percutaneous balloon compression of the gasserian ganglion in trigeminal neuralgia. Long-term results in 150 cases. Acta Neurochir (Wien). 1995; 136: 72-74.

11 Urculo E, Alfaro R, Arrazola M, et al. Trochlear nerve palsy after repeated percutaneous balloon compression for recurrent trigeminal neuralgia: Case report and pathogenic considerations. Neurosurgery. 2004; 54 : 505-508; discussion 8-9.

12 Asplund P, Linderoth B, Bergenheim AT. The predictive power of balloon shape and change of sensory functions on outcome of percutaneous balloon compression for trigeminal neuralgia. J Neurosurg. 2010; 113: 498-507.

13 James EA, Kibbler CC, Gillespie SH. Meningitis due to oral streptococci following percutaneous glycerol rhizotomy of the trigeminal ganglion. J Infect. 1995; 31 55-57.

14 Göçer A, Cetinalp E, Tuna M, et al. Fatal complication of the percutaneous radiofrequency trigeminal rhizotomy. Acta Neurochir (Wien). 1997; 139: 373-374.

15 Harrigan MR, Chandler WF. Abducens nerve palsy after radiofrequency rhizolysis for trigeminal neuralgia: Case report. Neurosurgery. 1998; 43: 623-625.

\section{Conclusion}

Dyna-CT demonstrates advantages in assisting PMC. It facilitates cannulation of the FO, aids in the identification and compression of an ideal balloon configuration with exact volume which provided good outcomes and few complications.

16 Gökalp H, Kanpolat Y, Tumer B. Carotid-cavernous fistula following percutaneous trigeminal ganglion approach. Clin Neurol Neurosurg. 1980; 82: 269-272.

17 Alvernia J, Sindou M, Nguyen D, et al. Percutaneous approach to the foramen ovale: An anatomical study of the extracranial trajectory with the incorrect trajectories to be avoided. Acta Neurochir (Wien). 2010; 152: 1043-1053.

18 Ugur HC, Savas A, Elhan A, et al. Unanticipated complication of percutaneous radiofrequency trigeminal rhizotomy: Rhinorrhea: Report of three cases and a cadaver study. Neurosurgery. 2004; 54: 1522-1524; discussion 4-6.

19 Meng FG, Wu CY, Liu YG, et al. Virtual reality imaging technique in percutaneous radiofrequency rhizotomy for intractable trigeminal neuralgia. J Clin Neurosci. 2009; 16: 449-451.

20 Van Gompel JJ, Kallmes DF, Morris JM, et al. DynaCT as an imaging adjunct to routine percutaneous balloon compression for trigeminal neuralgia. Stereotact Funct Neurosurg. 2009; 87: 330-333.

21 Park SS, Lee MK, Kim JW, et al. Percutaneous balloon compression of trigeminal ganglion for the treatment of idiopathic trigeminal neuralgia: Experience in 50 patients. J Korean Neurosurg Soc. 2008; 43: 186-189.

22 Skirving DJ, Dan NG. A 20-year review of percutaneous balloon compression of the trigeminal ganglion. J Neurosurg. 2001; 94: 913-917.

23 Fransen, P. Fluoroscopic exposure during percutaneous balloon compression of the Gasserian ganglion. J Neurointerv Surg. 2012; [Epub ahead of print].

Zhang Zhenxing, MD, Ph.D

Department of Neurosurgery The first affiliated hospital of Liaoning Medical University No. 2 Renmin Street, Guta area Jinzhou, Liaoning 121001 China E-mail: doctorzhangzx@126.com 